\title{
1 Oil Production from Mild Pyrolysis of Low-rank Coal in Molten
}

2

3

4 Jenny Rizkiana ${ }^{1}$, Guoqing Guan ${ }^{1,2^{*}}$, Wahyu Bambang Widayatno ${ }^{1}$, Xiaogang Hao $^{3}$,

$6{ }^{1}$ Graduate School of Science and Technology, Hirosaki University, 1-Bunkyocho,

$8{ }^{2}$ North Japan Research Institute for Sustainable Energy (NJRISE), Hirosaki University,

9

$10{ }^{3}$ School of Chemistry and Chemical Engineering, Taiyuan University of Technology,

11 Taiyuan 030024, China

12

13

14

15

16

${ }^{*}$ Tel.: $\quad+81-17-762-7756$

E-mail:

guan@hirosaki-u.ac.jp

(G. Guan);

abuliti@hirosaki-u.ac.jp (A. Abudula)

18 


\section{Abstract}

20 The present study focused on the utilization of molten carbonate salts as a media for the

21 pyrolysis process to produce oil from low-rank coal. A ternary eutectic mix of alkali

22 carbonate salts $\left(\mathrm{Li}_{2} \mathrm{CO}_{3}, \mathrm{Na}_{2} \mathrm{CO}_{3}\right.$, and $\left.\mathrm{K}_{2} \mathrm{CO}_{3}\right)$ was used to pyrolyze two kinds of

23 low-rank coals. The effect of molten salt to the reactivity of coal was investigated by

24 comparing the thermal decomposition profile of coal before and after it was mixed with

25 the molten salt. The oil yield and its composition were also investigated. The results

26 showed that the reactivity of the coal increased when the pyrolysis was performed in the

27 molten salt. The molten salt increased the pyrolysis conversion about 16.5 and $16.4 \%$

28 for Loy yang and Xinghe coals, respectively, when they were pyrolyzed at $600{ }^{\circ} \mathrm{C}$. The

29 use of molten salt increased the oil yield since it can rapidly heat the coal to make the

30 pyrolysis occur effectively. The total hydrocarbon content in the oil also increased about

$31 \quad 13.6$ and $11.0 \%$ for Loy yang and Xinghe coals, respectively. However, the molten

32 carbonate salts failed to retain the sulfuric compound during the pyrolysis period due to

33 the short residence time of oil in the molten salt phase.

34 Keywords: Molten carbonate salts; Oil production; Low rank coal; Mild pyrolysis. 


\section{Introduction}

38 Oil contributes about 33\% of global energy consumption in 2013 [1]. Assuming

39 that the level of consumption remains constants over years and no more oil reserves are

40 found, it is believed that petroleum will deplete within a couple of decades. Based on

412013 data, the world oil reserves would only sufficient to meet 53.3 years of global

42 production [1]. Alternative sources must be found and coal is one of the attractive

43 option. Coal still has a longer depletion time compared with other fossil fuels such as

44 natural gas and crude oil. Furthermore, it is considered as a low-cost fuel. Coal

45 utilization process is a mature technology yet still attractive to be researched. The recent

46 researches on coal are focused on how to utilize low-rank coal effectively since about

47 half of the coal reserves are in the low-rank state (lignite and sub bituminous) [2, 3, 4, 5,

$48 \quad 6,7,8,9,10]$.

49 Oil production from coal via thermal processing such as pyrolysis has been done

50 for years. In general, a relatively high temperature process is required to obtain oil from

51 the coal $[11,12,13]$. Some researchers try to mix the coal with biomass to decrease the

52 processing temperature $[14,15,16,17,18,19,20]$. However, other problems arise

53 when the coal is mixed with biomass. Biomass contains high amount of oxygen so that

54 the pyrolytic oil contains quite high amount of oxygenated compound with low oil 
55 quality [21, 22, 23]. The use of the catalyst such as zeolite may improve the oil quality

56 by after upgrading process [24, 25, 26].

57 Pyrolysis in molten salt media can be considered as an attractive option to increase

58 the pyrolysis rate as well as the oil quality at relatively low temperature. Molten salt is

59 an ionic crystal which melts into ionic liquid at high temperature. Molten salt provides

60 several advantages, such as large heat capacity, good dissolution ability, good thermal

61 conductivity, and also it has a catalytic activity for certain reactions [27, 28]. Recently,

62 the molten salt has been exploited to assist many kinds of processes, such as for heat

63 transfer fluid in nuclear power plant [29], heat storage media for solar power plant [30,

64 31], electrolyte in the fuel cells system [32, 33], and catalyst for chemical reactions [34,

$6535]$.

66 Certain kinds of salts were also utilized to assist thermal conversion of organic

67 matters. Matsunami et al. [36] have successfully utilized the mix of $\mathrm{K}_{2} \mathrm{CO}_{3}$ and $\mathrm{Na}_{2} \mathrm{CO}_{3}$

68 to increase the gasification rate of coal. The similar result was also obtained by

69 utilization of binary and ternary mix of carbonate salts [37,38]. However, most of their

70 studies were focused on the gas production at high temperature. The use of molten salts

71 to produce oil was done by Jiang et al. [39] who utilized the mix of chloride salts and

72 nitrate salts, but they found that due to the strong oxidizing effect of the salts, some of 
73 the obtained oil might undergo the secondary cracking reactions and thus increasing the

74 gas yield [27, 39]. In the present study, the ternary eutectic mix of carbonate salts

$75\left(\mathrm{Li}_{2} \mathrm{CO}_{3}-\mathrm{Na}_{2} \mathrm{CO}_{3}-\mathrm{K}_{2} \mathrm{CO}_{3}\right)$ was utilized as the media for pyrolyzing the low-rank coal

76 to produce oil. The melting point of the salts mix is low enough so that it is possible to

77 be utilized at low temperature. The effect of the adding salts was investigated by

78 analyzing the product distribution and the chemical composition of the pyrolytic oil.

$80 \quad$ 2. Experimental

$81 \quad 2.1$ Feedstock and molten salt media

82 Two kinds of low rank coals (i.e. Australian Loy yang coal and Chinese Xinghe

83 coal) were used as the feedstock samples. The proximate and ultimate analyses of the

84 samples were presented in Table 1 . Based on the preliminary experiment, to make sure

85 that all coal particle can be smoothly dropped into the salt media for the fast pyrolysis,

86 the samples were ground and sieved to particle size of 1-2.8 $\mathrm{mm}$ and then dried at 105

$87{ }^{\circ} \mathrm{C}$ overnight in the oven to remove their moisture content. The remaining moisture was

88 analyzed by using moisture content analyzer (MX50, AND, Japan).

89 Mixture of alkali carbonate salts (lithium carbonate, sodium carbonate, and

90 potassium carbonate, Wako, Japan) was utilized as the pyrolysis media. The salts were 
91 mixed in a ball mill at eutectic composition (29.8\%-mol $\mathrm{Na}_{2} \mathrm{CO}_{3}+44.1 \%-\mathrm{mol}_{2} \mathrm{CO}_{3}+$

92 26.1\%-mol $\mathrm{K}_{2} \mathrm{CO}_{3}$ ). Eutectic composition was chosen since it has low melting

93 temperature and thus it can be utilized for low temperature pyrolysis. Thermal stability

94 of the salt mixture as well as its melting point were observed by using a

95 thermogravimetric/differential thermal analyzer/TGA-DTA (DTG-60H, Shimadzu, 96 Japan).

97

98

Table 1 Proximate and ultimate analysis of the coal samples

99

100 The effect of molten carbonate salts on the reactivity of the coal was examined by

101 using a Thermogravimetric/Differential Thermal Analyzer/TGA-DTA (DTG-60H,

102 Shimadzu, Japan). The coal sample and the salt were homogeneously mixed at

103 coal-to-salt weight ratio of 1:0, 1:1, 1:5, 1:10, and 1:20 by mixing $1 \mathrm{mg}$ of coal sample

104 with $1,5,10$, and $20 \mathrm{mg}$ of salt mixture, respectively. They were heated to a

105 temperature of $600{ }^{\circ} \mathrm{C}$ at a heating rate of $10{ }^{\circ} \mathrm{C} / \mathrm{min}$. The coal reactivity was examined

106 by comparing the TGA results before and after it was mixed with the salt.

107

108

2.2 Pyrolysis setup 
110 batch reactor was used as the pyrolyzer. 1 gram of sample was put in the sample holder

111 while $10 \mathrm{~g}$ of salts were put in the main reactor. Based on the preliminary experiments,

112 it is found that 10 gram of salts is enough to immerse the inner tube to make sure that

113 coal sample can contact with the salts well during pyrolysis. The reactor was firstly

114 flushed by using argon gas to remove the air out of the system. Meanwhile, the electric

115 furnace was turned on to heat up the main reactor until it reached the desired pyrolysis

116 temperature, which was varied from $450-600{ }^{\circ} \mathrm{C}$. The reactor was kept at the desired

117 temperature for $1 \mathrm{~h}$ to completely melt the salt and formed a eutectic liquid. Pyrolysis

118 process was started by opening the feeder valve to let the sample dropped down to the

119 molten salt media via the central tube inserted in the molten salt with carrier argon gas.

120 In order to let coal mix with molten salt well, the molten salt layer was continuously

121 bubbled with argon gas. The total reaction was fixed at $10 \mathrm{~min}$. The volatile product

122 was carried out of the reactor by the argon gas with a total flow rate of $100 \mathrm{~cm}^{3} / \mathrm{min}$

123 (STP), and then flowed to the condenser which consists of two series bottles placed in

124 the ice-water bath. The first bottle was used to collect the heavy tar while the second

125 condenser was filled by $20 \mathrm{ml}$ of acetone to trap the light tar. Non condensable gas was

126 passed through the gas purifier and collected in the gas bag for further analysis using a 
127 gas chromatograph (GC/TCD, Agilent 7890A, USA). The composition of the obtained

128 oil in the first and second condensers were analyzed by using a gas

129 chromatography/mass spectroscopy (GC/MS QP2010, Shimadzu, Japan) and their water

130 content were analyzed by using Karl-Fisher Titration method (MKS-500, KEM, Japan).

131 The remaining solid in the reactor was defined as salts and char.

132

Fig.1 Schematic diagram of the pyrolysis setup

133

134 3. Results and discussion

$135 \quad 3.1$ Characterization of molten salts

136 Thermal characterization of the molten salt was done by using the TGA/DTA and

137 the results are presented in Fig.2. The salt obtained from ball-milling process was

138 heated until $600{ }^{\circ} \mathrm{C}$ at a heating rate of $10{ }^{\circ} \mathrm{C} / \mathrm{min}$ and the TGA/DTA results are shown

139 in the Fig.2a. Once it was cooled down, the salt was reheated at the same heating

140 condition $\left(10{ }^{\circ} \mathrm{C} / \mathrm{min}\right.$ until it reached $\left.600{ }^{\circ} \mathrm{C}\right)$ and the TGA/DTA results are shown in

141 the Fig.2b. TGA result (residual weight profile) of the salts after ball-milled process in

142 Fig.2a shows that the sample weight decreased about 3.6\% after the salts was heated

143 until $110{ }^{\circ} \mathrm{C}$ due to the evaporation of the moisture contained in the salt. After all the

144 water was evaporated, no weight decreasing was observed even until the temperature of

145 salts reached $600{ }^{\circ} \mathrm{C}$ indicating that the molten carbonate salts is thermally stable. As for 
146 the reheated salt (Fig.2b), no weight loss was observed since no more moisture was

147 contained in the salt

148

149 Fig.2 TGA/ DTA profile of the salts after (a) ball-milled and (b) re-melted.

151 so that the weight remained constant until the end of heating. DTA result in Fig.2a

152 shows that two peaks were observed for the after-ball-milled salt. The first appeared at

153 the temperature of about $100{ }^{\circ} \mathrm{C}$, which correlated with the evaporation of the moisture

154 in the salt while the second peak appeared at the temperature of about $430{ }^{\circ} \mathrm{C}$, which

155 correlated with the salt melting. For the reheated salt (Fig.2b), only one peak was

156 observed at about $400{ }^{\circ} \mathrm{C}$ which correlated with the salt melting. The onset temperature

157 analysis showed that the melting temperature for the salt after ball-milling process was

$158429{ }^{\circ} \mathrm{C}$ while for the reheated salt was $395{ }^{\circ} \mathrm{C}$. The melting point results indicate that

159 mixing the salts in a ball mill cannot completely homogenize the mixture. The eutectic

160 mix of the salts can be obtained after the mixture was melted. However, since the

161 melting point was still lower than the desired pyrolysis temperature, salt mixture from

162 the ball-mill mixing process can be utilized as the mild pyrolysis media. 


\section{$164 \quad 3.2$ The effect of adding molten salt on the coal reactivity}

165 A thermogravimetric analyzer was utilized to investigate the effect of molten salt

166 addition on the reactivity of the coal. The change of the coal reactivity in the presence

167 of molten salts was determined by comparing the thermal decomposition profile of the

168 coal before and after mixed with the molten salts. Fig.3 shows the residual weight of

169 Loy yang coal as the function of the temperature before and after mixed with the

170 carbonate molten salts at various ratio ( $1 \mathrm{mg}$ of coal mixed with 1, 5, 10, and $20 \mathrm{mg}$ of

171 salts). The samples were heated until $600{ }^{\circ} \mathrm{C}$ at a heating rate of $10{ }^{\circ} \mathrm{C} / \mathrm{min}$ in the

172 atmosphere of nitrogen. Herein, it should be noted that the moisture content of the salt

173 (as seen in the Fig.2) has been calculated and subtracted proportionally from each of the

174 thermal decomposition profile. From Fig.3, it can be seen that the addition of the molten

175 salt can increase the thermal conversion of the coal quite significantly. The conversion

176 of the coal increased from 46.8 to $52.1 \%$ at $600{ }^{\circ} \mathrm{C}$ when $1 \mathrm{mg}$ of the salt was added and

177 further increased to $58.5 \%, 61.6 \%$, and $63.8 \%$ when the salt amount was increased to 5,

178 10, and $20 \mathrm{mg}$, respectively.

179

180 Fig.3 Thermal decomposition profile of Loy yang coal before and after mixed with the various amount of molten salts. 
184 alkali species in the salt. Alkali metal species are known to have a good catalytic effect

185 on the pyrolysis and gasification [40, 41, 42, 43, 44]. Alkali metal species such as 186 potassium could interact with the carbon and form active carbon/potassium complex

187 which is easier to be decomposed [42]. Xu et al. [45] also found that the use of alkali

188 carbonate salts can promote the thermal decomposition of the organic matter and as

189 such, the conversion rate was increased and the pyrolysis time was shortened.

190 Furthermore, as seen in Fig.3, at the low salt amount (1 or $5 \mathrm{mg}$ ) addition, the coal

191 conversion increased after the temperature reached $400{ }^{\circ} \mathrm{C}$, but the conversion remained

192 almost the same as that without molten salt at the temperature lower than $400{ }^{\circ} \mathrm{C}$. At

193 low salt amount addition, only some parts of the coal can be contacted with the salt.

194 When the temperature reached $400{ }^{\circ} \mathrm{C}$, the salt started to melt to fluid phase and flow

195 into the coal samples. As a result, more coal can contact with the salt and result in the

196 increasing of the conversion. In contrast, at higher salt content (10 mg), the amount of

197 salt was high enough to make an effective contact with the coal samples so that the

198 conversion increased even before the salt melted. Further increasing of the salt content

199 to $20 \mathrm{mg}$ did not increase the conversion obviously since the effective contact could

200 already reach the maximum at the salt amount of $10 \mathrm{mg}$. As seen in Fig.3, there is no 
201 significant difference on the thermal decomposition profile of the coal when the salt

202 amount was increased from 10 to $20 \mathrm{mg}$. Similar result was observed by Jin et al. [46]

203 who found that catalytic effect of the molten salt achieved an optimum when the

204 biomass to catalyst weight ratio exceeded 1:10. The pyrolysis conversion should relate

205 with the coal distributed in the molten salt. When the sample is evenly distributed,

206 adding more salts will not give any significant effect on the coal pyrolysis.

207

208

\subsection{Product distribution}

209 Flash pyrolysis was performed in the dropdown batch reactor as seen in Fig.1. For

210 each run, 10 gram of salts were used to pyrolyze 1 gram of coal sample. 10 gram of

211 salts is considered to be appropriate amount of salts to catalyze 1 gram of coal since it is

212 enough to distribute in coal sample and make a good contact with each other. 10 gram

213 of salts was also enough to immerse the inner tube of the reactor to ensure the contact

214 between coal sample and the molten salts. Fig.4 compares the product distributions

215 from the pyrolysis of Loy yang coal (Fig.4a) and Xinghe coal (Fig.4b) without (shaded

216 graph) and with molten salt media (solid graph). Gas yield was obtained from GC/TCD

217 analysis result and the char yield was obtained from the remaining solid in the reactor

218 assuming that the amount of salt remained stable. The detail of gas yield calculation 
219 based on GC/TCD analysis is presented in the supplementary data. For the oil yield, it is

220 practically difficult to collect all the oil product from the reactor completely. Therefore,

221 oil yield was directly calculated from mass balance after subtracted by its water content

222 which was analyzed by using Karl-Fisher titration (KFT) method. The results in Fig.4

223 showed that the char yield decreased significantly when the coal samples were

224 pyrolyzed in the molten salts for Loy yang as well as Xinghe coals. The use of molten

225 carbonate salts as the pyrolysis media decreased the char yield from 55.3 to $38.8 \%$ for

226 Loy yang coal and from 61.3 to $49.5 \%$ for Xinghe coal at $600{ }^{\circ} \mathrm{C}$. The char yield

227 decreasing was still observed even at lower temperature. As stated above, alkali metal

228 species in the salt could increase the reactivity of the coal and thus the coal is easier to

229 be pyrolyzed. Furthermore, in the liquid phase, molten salt can transfer the heat more

230 effectively since generally they have higher thermal conductivity. Once contacted with

231 the molten salt, the coal would be rapidly heated and thus the pyrolysis happens

232 effectively in a very short time. Here, it should be noted that since Loy yang coal has

233 more volatile matter than Xinghe coal, its reactivity was also higher [47] and thus less

234 char was produced from Loy yang coal than that from Xinghe coal during the pyrolysis

235 process.

236 
237 Fig.4 Product yield distribution from pyrolysis of coal with molten salts media (solid area) and without molten salts media (Shaded area) for (a) Loy yang coal and (b)

Xinghe coal.

temperature but the increase became more significant when the temperature was

244 increased up to $600{ }^{\circ} \mathrm{C}$. As seen in Fig.5, significant increases were observed for $\mathrm{CO}_{2}$

and $\mathrm{H}_{2}$. At $600{ }^{\circ} \mathrm{C}$, the use of molten salts increased hydrogen production for about

$24670.3 \%$ and $\mathrm{CO}_{2}$ production for about $66.6 \%$. In the presence of $\mathrm{CO}_{2}$ or $\mathrm{H}_{2} \mathrm{O}$, alkali

247 carbonate salt could catalyze the gasification of coal based on following reactions [48]:

248 In the presence of $\mathrm{H}_{2} \mathrm{O}$

$249 \mathrm{M}_{2} \mathrm{CO}_{3}+2 \mathrm{C} \rightarrow 2 \mathrm{M}+3 \mathrm{CO}$

250

$2 \mathrm{M}+2 \mathrm{H}_{2} \mathrm{O} \rightarrow 2 \mathrm{MOH}+\mathrm{H}_{2}$

251

$2 \mathrm{MOH}+\mathrm{CO} \rightarrow \mathrm{M}_{2} \mathrm{CO}_{3}+\mathrm{H}_{2}$

252 In the presence of $\mathrm{CO}_{2}$

$253 \mathrm{M}_{2} \mathrm{CO}_{3}+2 \mathrm{C} \rightarrow 2 \mathrm{M}+3 \mathrm{CO}$

$2542 \mathrm{M}+\mathrm{CO}_{2} \rightarrow \mathrm{M}_{2} \mathrm{O}+\mathrm{CO}$

$\mathrm{M}_{2} \mathrm{O}+\mathrm{CO}_{2} \rightarrow \mathrm{M}_{2} \mathrm{CO}_{3}$ 
256 where $\mathrm{M}$ is an alkali metal. Based on above mechanism, the use of alkali carbonate

257 might increase the yield of hydrogen gas. The CO amount in the obtained gas product

258 did not increase since it might be converted into $\mathrm{CO}_{2}$ via water gas shift reaction. As a

259 result, the $\mathrm{CO}_{2}$ increased. The increasing yield of $\mathrm{CO}_{2}$ might also come from the

260 decomposition of the carbonate salt due to the presence of steam as follow [38]:

$261 \mathrm{M}_{2} \mathrm{CO}_{3}+\mathrm{H}_{2} \mathrm{O} \rightarrow 2 \mathrm{MOH}+\mathrm{CO}_{2}$

262 where $\mathrm{M}$ is an alkali metal. However, in the present study, the salt decomposition is

263 negligible since the amount of steam is very limited so that it cannot interact intensively

264 with the salts. Therefore, the increasing amount of $\mathrm{CO}_{2}$ should be mainly due to $\mathrm{CO}$

265 conversion.

266 Compared with the decreasing yield of char, the gas yield increasing was not

267 significant as seen in Fig.4. It indicates that the use of molten carbonate salts could

268 improve the liquid yield. Since the temperature was quite low and the residence time

269 was also short, the secondary reaction, which possibly converts volatiles to produce

270 more gas, could be avoided and thus the pyrolysis process tends to produce more liquid

271 than gas. However, the oil yield was slightly decreased when the temperature was

272 increased from 550 to $600{ }^{\circ} \mathrm{C}$. Herein, the oil yield decreased from 33.9 to $30.9 \%$ for the

273 Loy yang coal and from 31.1 to $27.7 \%$ for the Xinghe coal. The slight decreasing of the 
274 oil yield is probably caused by the thermal cracking some parts of oil and production of

275 water as the byproduct. As seen in the figure, the yield of water was also increased from

27621.2 to $24.8 \%$ for the Loy yang coal, indicating that those water could probably be

277 produced from the cracking of the oil.

278

279

Fig.5 Gas composition obtained from pyrolysis of Xinghe coal without molten salt media (shaded area) and with molten salt media (solid area)

281

282

\subsection{The effect of the molten salt on oil composition}

283 Fig.6 shows the composition of the obtained oil from the pyrolysis process with and

284 without molten salt media at $600{ }^{\circ} \mathrm{C}$. For the Loy yang coal (Fig.6a), the original

285 pyrolytic oil contained about 50.9\% hydrocarbon compounds. Most oxygenated

286 compounds appeared in the form of phenols, followed by alcohols, ketones, and small

287 amount of carboxylates. When the sample was pyrolyzed in the molten salt media,

288 hydrocarbon content increased significantly to $64.5 \%$ while the oxygenated compounds

289 such as phenol and alcohol decreased about $11.5 \%$ and $9.0 \%$, respectively. The increase

290 of hydrocarbon content was due to the higher conversion of the coal which

291 characterized by less char production. Less char production implies that the coal sample

292 tends to produce more volatiles rather than remains as char. In the volatiles, more 
293 hydrocarbons were formed than the oxygenated compounds since coal has a very low

294 content of oxygen. Furthermore, at high temperature, some parts of the oil were cracked.

295 It is possible that some of the

296 Fig.6 Composition of the oil from pyrolysis of (a) Loy yang coal and (b) Xinghe coal with and without salt molten media at $600{ }^{\circ} \mathrm{C}$

298

299

oxygenated compounds were cracked to hydrocarbons, and water was also produced as

300 the byproduct. As a result, water content in the oil was increased as seen in Fig.4.

301 Moreover, alkali and alkaline earth metal species were found to be able to decrease the

302 amount of oxygenated compound to form less oxygenated ones [49, 50]. Similar results

303 were obtained for the Xinghe coal (Fig.6b). The original pyrolytic oil was shown to

304 have a very high content of phenols (about 63.2\%). After it was pyrolyzed in the molten

305 salt media, the phenol content decreased and the hydrocarbons increased from 15.5 to

$306 \quad 26.5 \%$.

307 It should be noted from Fig.6b that sulfuric compounds in the oil increased from

3083.5 to $6.5 \%$ when the molten salt media was used. The increase of sulfuric compounds

309 was caused by the increase of pyrolysis conversion. When the pyrolysis conversion

310 increased, more sulfuric elements was also released from the char matrix. Theoretically, 
311 carbonate salts have an ability to capture sulfuric compounds according to the following

312 reaction:

313 In the form of organic compound [51]

$3142 \mathrm{C}_{a} \mathrm{H}_{b} \mathrm{~S}_{c}+2 \mathrm{cM}_{2} \mathrm{CO}_{3}+(2 a+b / 2+3 c) \mathrm{O}_{2} \rightarrow 2(a+c) \mathrm{CO}_{2}+b \mathrm{H}_{2} \mathrm{O}+2 c \mathrm{M}_{2} \mathrm{SO}_{4}$

$315 \quad$ In the form of $\mathrm{H}_{2} \mathrm{~S}[52]$

$316 \mathrm{H}_{2} \mathrm{~S}+\mathrm{M}_{2} \mathrm{CO}_{3} \cdot 3 \mathrm{H}_{2} \mathrm{O} \rightarrow \mathrm{CO}_{2}+4 \mathrm{H}_{2}+\mathrm{M}_{2} \mathrm{SO}_{4}$

317 If assume that the sulfur behaves as elemental sulfur [53]

$318 \mathrm{~S}+1 / 2 \mathrm{C}+\mathrm{M}_{2} \mathrm{CO}_{3} \rightarrow \mathrm{M}_{2} \mathrm{~S}+3 / 2 \mathrm{CO}_{2}$

319 The most possible reaction to be happened is the reaction (10) if it is assumed that the

320 sulfur behaves as elemental sulfur. However, reaction (10) is a highly endothermic

321 reaction [53] so that it needs high temperature to occur effectively. In the present study,

322 pyrolysis was done at relatively low temperature and low reaction time and thus

323 reaction (10) could not occur effectively. Coal has a higher specific gravity than the

324 salts, but after volatile matter released, the remaining char became lighter. Sugiura et al.

325 [52] reported that the samples floated on the surface of the molten salts once it entered

326 the salt media. The short contact time causes the sulfur cannot be captured effectively

327 since the reaction rate is low [52]. In addition, the oxygen was absent in the reaction

328 system and thus reaction (8) could not happen. The sulfuric elements were possibly 
329 released either in the form of gas $\left(\mathrm{SO}_{2}\right.$ and $\left.\mathrm{H}_{2} \mathrm{~S}\right)$ or organic sulfur, such as thiophene

330 and thiol. The organic sulfur were easily mixed with the oil. Therefore, more sulfuric

331 components were detected in the obtained oil.

332 Major compounds detected in the oil obtained from pyrolysis of Loy yang coal in 333 the molten carbonate salts media at various temperatures are presented in Table 2. As

334 seen in Fig.6a, the pyrolytic oil was dominated by hydrocarbon components. Table 2

335 shows that more than half of the hydrocarbons were in the form of aromatics (benzene,

336 toluene, and their derivatives). Most of the oxygenated components were found in the

337 form of phenolic compounds, such as phenol and cresol. Other oxygenated components

338 were also found in the form of ketones and alcohols. As shown in Table 2, the amount

339 of hydrocarbons was decreased with the decreasing of temperature. The amount of

340 hydrocarbons may increase along with the increasing of coal conversion. It can be seen

341 in Fig.4 that the char yield was continuously decreased along with the increasing of

342 pyrolysis temperature from 450 to $600{ }^{\circ} \mathrm{C}$. It indicates that further conversion of coal

343 could increase the content of hydrocarbons.

345 Table 2 Main chemical compositions of the obtained oil from the pyrolysis of Loy yang 346 coal. 


\section{4. Conclusions}

349 Eutectic mix of alkali carbonate salts was employed to assist pyrolysis of the low

350 rank coals for oil production. Some properties of the molten salt, such as good catalytic

351 activity and high thermal conductivity were exploited to increase the performance of the

352 pyrolysis process for oil production at mild temperature. The results showed that the use

353 of molten carbonate salts significantly enhanced the liquid production yield by

354 increasing the reactivity of the coal. The molten salt was also able to transfer the heat

355 rapidly so that the pyrolysis could occur in a very short time and thus the further

356 decomposition of liquid to produce gas could be avoided. The use of molten carbonate

357 salt also showed a good activity to increase the oil quality by increasing the

358 hydrocarbon content in the oil. Although molten carbonate salt has a potential to retain

359 the unwanted component such as sulfur, it would not occur if the temperature is too low

360 while the contact time is too short. Extending contact time is necessary if molten

361 carbonate salt is expected to separate the sulfur with the pyrolysis product. 
364 This work is supported by Strategic International Collaborative Research Program

365 (SICORP), Japan Science and Technology (JST), Japan, and the International Joint

366 Research Project of Shanxi Province (No.2015081051and 2015081052 ). The authors

367 would like to thank Professor Koyo Norinaga at Kyushu University and Dr. Koichi

368 Matsuoka at National Institute of Advanced Industrial Science and Technology to

369 provide coal samples. J. Rizkiana and W. B. Widayatno gratefully acknowledge the

370 scholarship from Ministry of Education, Culture, Sport, Science, and Technology

371 (MEXT) of Japan.

372 References

373 [1] BPstats. BP statistical review of world energy 2014. London 2014.

374 [2] Bhutto AW, Bazmi AA, Zahedi G. Underground coal gasification: From

375 fundamentals to applications. Progress in Energy and Combustion Science.

$376 \quad$ 2013;39:189-214.

377 [3] Rizkiana J, Guan G, Widayatno WB, Hao X, Li X, Huang W, et al. Promoting effect

378 of various biomass ashes on the steam gasification of low-rank coal. J Appl Energy.

$379 \quad$ 2014;133:282-8. 
380 [4] Rizkiana J, Guan G, Widayatno WB, Hao X, Huang W, Tsutsumi A, et al. Effect of

381 biomass type on the performance of cogasification of low rank coal with biomass at

382 relatively low temperatures. Fuel. 2014;134:414-9.

383 [5] Sulman EM, Alferov VV, Kosivtsov YY, Sidorov AI, Misnikov OS, Afanasiev AE,

384 et al. The development of the method of low-temperature peat pyrolysis on the

385 basis of alumosilicate catalytic system. Chemical Engineering Journal.

$386 \quad$ 2007;134:162-7.

387 [6] Ahmed II, Gupta AK. Experiments and stochastic simulations of lignite coal during

388 pyrolysis and gasification. J Appl Energy. 2013;102:355-63.

389 [7] Yilgin M, Pehlivan D. Volatiles and char combustion rates of demineralised lignite

$390 \quad$ and wood blends. J Appl Energy. 2009;86:1179-86.

391 [8] Guo Z, Wang Q, Fang M, Luo Z, Cen K. Thermodynamic and economic analysis of

392 polygeneration system integrating atmospheric pressure coal pyrolysis technology

393 with circulating fluidized bed power plant. J Appl Energy. 2014;113:1301-14.

394 [9] Zeng X, Wang F, Li H, Wang Y, Dong L, Yu J, et al. Pilot verification of a low-tar

395 two-stage coal gasification process with a fluidized bed pyrolyzer and fixed bed 396 gasifier. J Appl Energy. 2014;115:9-16. 
397 [10] Rady AC, Giddey S, Kulkarni A, Badwal SPS, Bhattacharya S, Ladewig BP.

398 Direct carbon fuel cell operation on brown coal. J Appl Energy. 2014;120:56-64.

399 [11] Ding L, Zhou Z, Guo Q, Huo W, Yu G. Catalytic effects of Na2CO3 additive on $400 \quad$ coal pyrolysis and gasification. Fuel. 2015;142:134-44.

401 [12] Lievens C, Ci D, Bai Y, Ma L, Zhang R, Chen JY, et al. A study of slow pyrolysis 402 of one low rank coal via pyrolysis-GC/MS. Fuel Processing Technology. $403 \quad$ 2013;116:85-93.

404 [13] Dong J, Cheng Z, Li F. PAHs emission from the pyrolysis of Western Chinese coal. $405 \quad$ Journal of Analytical and Applied Pyrolysis. 2013;104:502-7.

406 [14] Blesa MJ, Miranda JL, Moliner R, Izquierdo MT, Palacios JM. Low-temperature 407 co-pyrolysis of a low-rank coal and biomass to prepare smokeless fuel briquettes. 408 Journal of Analytical and Applied Pyrolysis. 2003;70:665-77.

409 [15] Li S, Chen X, Liu A, Wang L, Yu G. Study on co-pyrolysis characteristics of rice 410 straw and Shenfu bituminous coal blends in a fixed bed reactor. Bioresource 411 technology. 2014;155C:252-7.

412 [16] Soncini RM, Means NC, Weiland NT. Co-pyrolysis of low rank coals and biomass:

$413 \quad$ Product distributions. Fuel. 2013;112:74-82. 
414 [17] Sonobe T, Worasuwannarak N, Pipatmanomai S. Synergies in co-pyrolysis of Thai

415 lignite and corncob. Fuel Processing Technology. 2008;89:1371-8.

416 [18] Weiland NT, Means NC, Morreale BD. Product distributions from isothermal

417 co-pyrolysis of coal and biomass. Fuel. 2012;94:563-70.

418 [19] Wu Z, Wang S, Zhao J, Chen L, Meng H. Synergistic effect on thermal behavior

419 during co-pyrolysis of lignocellulosic biomass model components blend with

420 bituminous coal. Bioresource technology. 2014;169C:220-8.

421 [20] Lu K-M, Lee W-J, Chen W-H, Lin T-C. Thermogravimetric analysis and kinetics

422 of co-pyrolysis of raw/torrefied wood and coal blends. J Appl Energy. $423 \quad$ 2013;105:57-65.

424 [21] Guo X, Wang S, Wang Q, Guo Z, Luo Z. Properties of Bio-oil from Fast Pyrolysis 425 of Rice Husk. Chin J Chem Eng. 2011;19:116-21.

426 [22] Xiu S, Shahbazi A. Bio-oil production and upgrading research: A review. 427 Renewable and Sustainable Energy Reviews. 2012;16:4406-14.

428 [23] Lehto J, Oasmaa A, Solantausta Y, Kytö M, Chiaramonti D. Review of fuel oil 429 quality and combustion of fast pyrolysis bio-oils from lignocellulosic biomass. J $430 \quad$ Appl Energy. 2014;116:178-90. 
431 [24] Aho A, Kumar N, Eränen K, Salmi T, Hupa M, Murzin DY. Catalytic pyrolysis of

432 woody biomass in a fluidized bed reactor: Influence of the zeolite structure. Fuel.

$433 \quad 2008 ; 87: 2493-501$.

434 [25] Li S, Chen J, Hao T, Liang W, Liu X, Sun M, et al. Pyrolysis of Huang Tu Miao

435 coal over faujasite zeolite and supported transition metal catalysts. Journal of

$436 \quad$ Analytical and Applied Pyrolysis. 2013;102:161-9.

437 [26] Mihalcik DJ, Mullen CA, Boateng AA. Screening acidic zeolites for catalytic fast

438 pyrolysis of biomass and its components. Journal of Analytical and Applied

$439 \quad$ Pyrolysis. 2011;92:224-32.

440 [27] Nygard HS, Olsen E. Review of thermal processing of biomass and waste in

441 molten salts for production of renewable fuels and chemicals. International Journal

442 of Low-Carbon Technologies. 2012.

443 [28] Jiang H, Wu Y, Fan H, Ji J. Hydrogen Production from Biomass Pyrolysis in

$444 \quad$ Molten Alkali. AASRI Procedia. 2012;3:217-23.

445 [29] Sabharwall P, Clark D, Glazoff M, Zheng G, Sridharan K, Anderson M. Advanced

446 heat exchanger development for molten salts. Nucl Eng Des. 2014;280:42-56.

447 [30] Peng Q, Yang X, Ding J, Wei X, Yang J. Design of new molten salt thermal energy

448 storage material for solar thermal power plant. J Appl Energy. 2013;112:682-9. 
449 [31] Fernández AG, Ushak S, Galleguillos H, Pérez FJ. Development of new molten

450 salts with LiNO3 and Ca(NO3)2 for energy storage in CSP plants. J Appl Energy.

$451 \quad 2014 ; 119: 131-40$.

452 [32] Tomczyk P. MCFC versus other fuel cells-Characteristics, technologies and 453 prospects. J Power Sources. 2006;160:858-62.

454 [33] Antolini E. The stability of molten carbonate fuel cell electrodes: A review of 455 recent improvements. J Appl Energy. 2011;88:4274-93.

456 [34] Matsumiya H, Hara T. Conversion of glucose into 5-hydroxymethylfurfural with

457 boric acid in molten mixtures of choline salts and carboxylic acids. Biomass and $458 \quad$ Bioenergy. 2014.

459 [35] Branco JB, Lopes G, Ferreira AC. Catalytic oxidation of methane over KCl-LnCl3 $460 \quad$ eutectic molten salts. Catal Commun. 2011;12:1425-7.

461 [36] Matsunami J, Yoshida S, Oku Y, Yokota O, Tamaura Y, Kitamura M. Coal 462 gasification with CO2 in molten salt for solar thermal-chemical energy conversion.

$463 \quad$ Energy. 2000;25:71-9.

464 [37] sheth A, Yeboah YD, Godavarty A, Xu Y, Agrawal PK. Catalytic gasification of 465 coal using eutectic salts: reaction kinetics with binary and ternary eutectic catalysts.

$466 \quad$ Fuel. 2003;82:305-17. 
467 [38] Hathaway BJ, Honda M, Kittelson DB, Davidson JH. Steam gasification of plant

468 biomass using molten carbonate salts. Energy. 2013;49:211-7.

469 [39] Jiang H, Ai N, Wang M, Ji DJ. Experimental Study on Thermal Pyrolysis of

$470 \quad$ Biomass in Molten Salt Media. Electrochemistry. 2009;77.

471 [40] Mitsuoka K, Hayashi S, Amano H, Kayahara K, Sasaoaka E, Uddin MA.

472 Gasification of woody biomass char with CO2: The catalytic effects of $\mathrm{K}$ and $\mathrm{Ca}$

473 species on char gasification reactivity. Fuel Processing Technology. 2011;92:26-31.

474 [41] Wang J, Jiang M, Yao Y, Zhang Y, Cao J. Steam gasification of coal char

475 catalyzed by K2CO3 for enhanced production of hydrogen without formation of

476 methane. Fuel. 2009;88:1572-9.

477 [42] Nzihou A, Stanmore B, Sharrock P. A review of catalysts for the gasification of 478 biomass char, with some reference to coal. Energy. 2013;58:305-17.

479 [43] Zhu ZH, Lu GQ, Yang RT. New Insights into Alkali-Catalyzed Gasification 480 Reactions of Carbon: Comparison of N2O Reduction with Carbon over Na and K $481 \quad$ Catalysts. Journal of Catalysis. 2000;192:77-87.

482 [44] Zhu W, Song W, Lin W. Catalytic gasification of char from co-pyrolysis of coal 483 and biomass. Fuel Processing Technology. 2008;89:890-6. 
484 [45] Xu Q, Ma X, Yu Z, Cai Z. A kinetic study on the effects of alkaline earth and alkali

485 metal compounds for catalytic pyrolysis of microalgae using thermogravimetry.

486 Appl Therm Eng. 2014;73:357-61.

487 [46] Jin G, Iwaki H, Arai N, Kitagawa K. Study on the gasification of

488 wastepaper/carbon dioxide catalyzed by molten carbonate salts. Energy.

$489 \quad 2005 ; 30: 1192-203$.

490 [47] Basu P. Combustion and Gasification in Fluidized Beds.: CRC Press; 2006.

491 [48] Iwaki H, Ye S, Katagiri H, Kitagawa K. Wastepaper gasification with CO2 or

492 steam using catalysts of molten carbonates. Applied Catalysis A: General.

$493 \quad 2004 ; 270: 237-43$.

494 [49] Mourant D, Wang Z, He M, Wang XS, Garcia-Perez M, Ling K, et al. Mallee

495 wood fast pyrolysis: Effects of alkali and alkaline earth metallic species on the

$496 \quad$ yield and composition of bio-oil. Fuel. 2011;90:2915-22.

497 [50] Zabeti M, Nguyen TS, Lefferts L, Heeres HJ, Seshan K. In situ catalytic pyrolysis

498 of lignocellulose using alkali-modified amorphous silica alumina. Bioresource

$499 \quad$ technology. 2012;118:374-81.

500 [51] Yao Z, Li J, Zhao X. Molten salt oxidation: a versatile and promising technology

501 for the destruction of organic-containing wastes. Chemosphere. 2011;84:1167-74. 
502 [52] Sugiura K, Minami K, Yamauchi M, Morimitsu S, Tanimoto K. Gasification

503 characteristics of organic waste by molten salt. J Power Sources. 2007;171:228-36.

504 [53] Trilling CA. Mass and Heat Balance for Coal Gasification by Atomics

505 International's Molten Salt gasification Process.

506 http://web.anl.gov/PCS/acsfuel/preprint\%

507 20archive/Files/Merge/Vol-22_2-0001.pdf. 


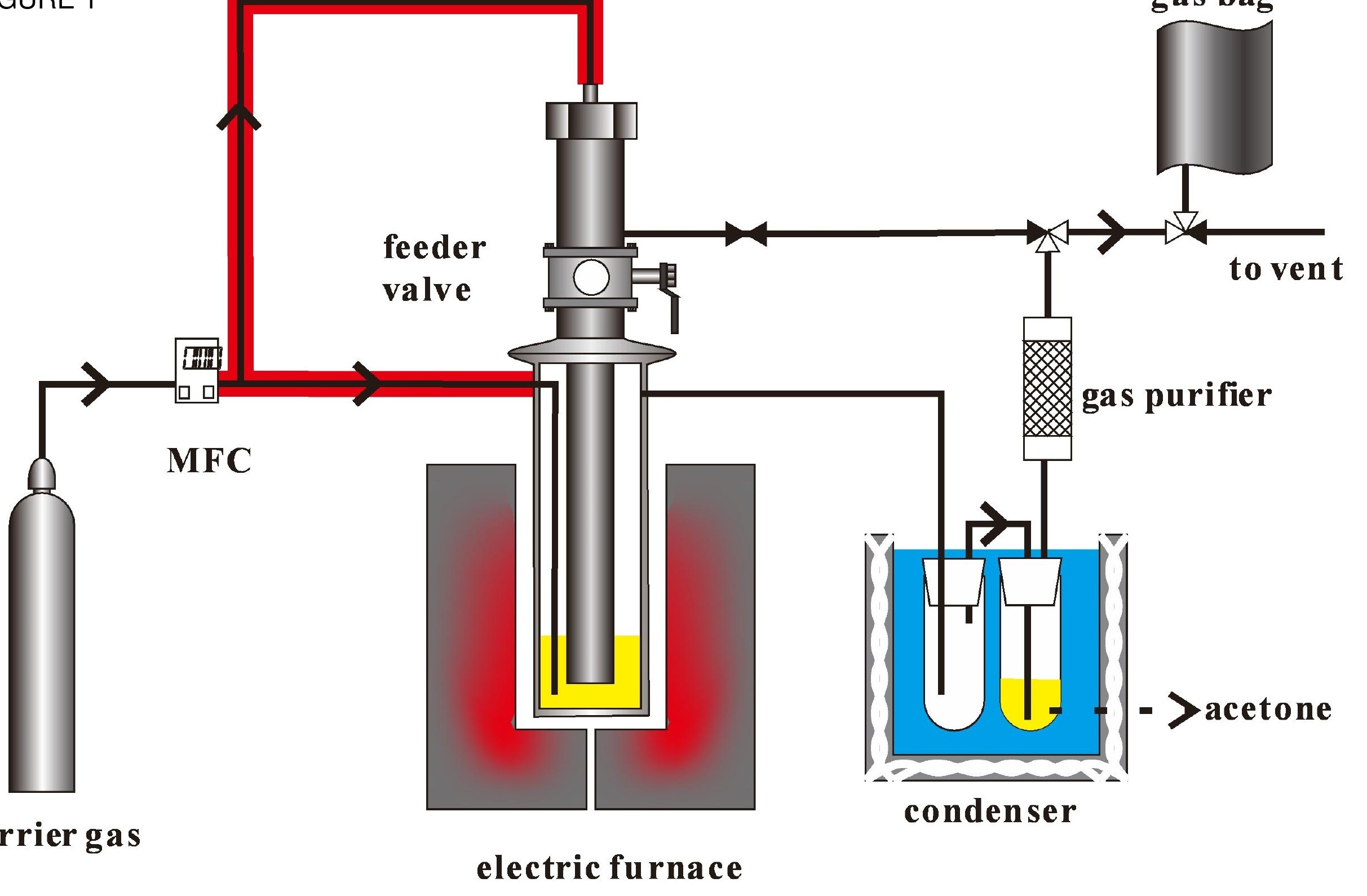




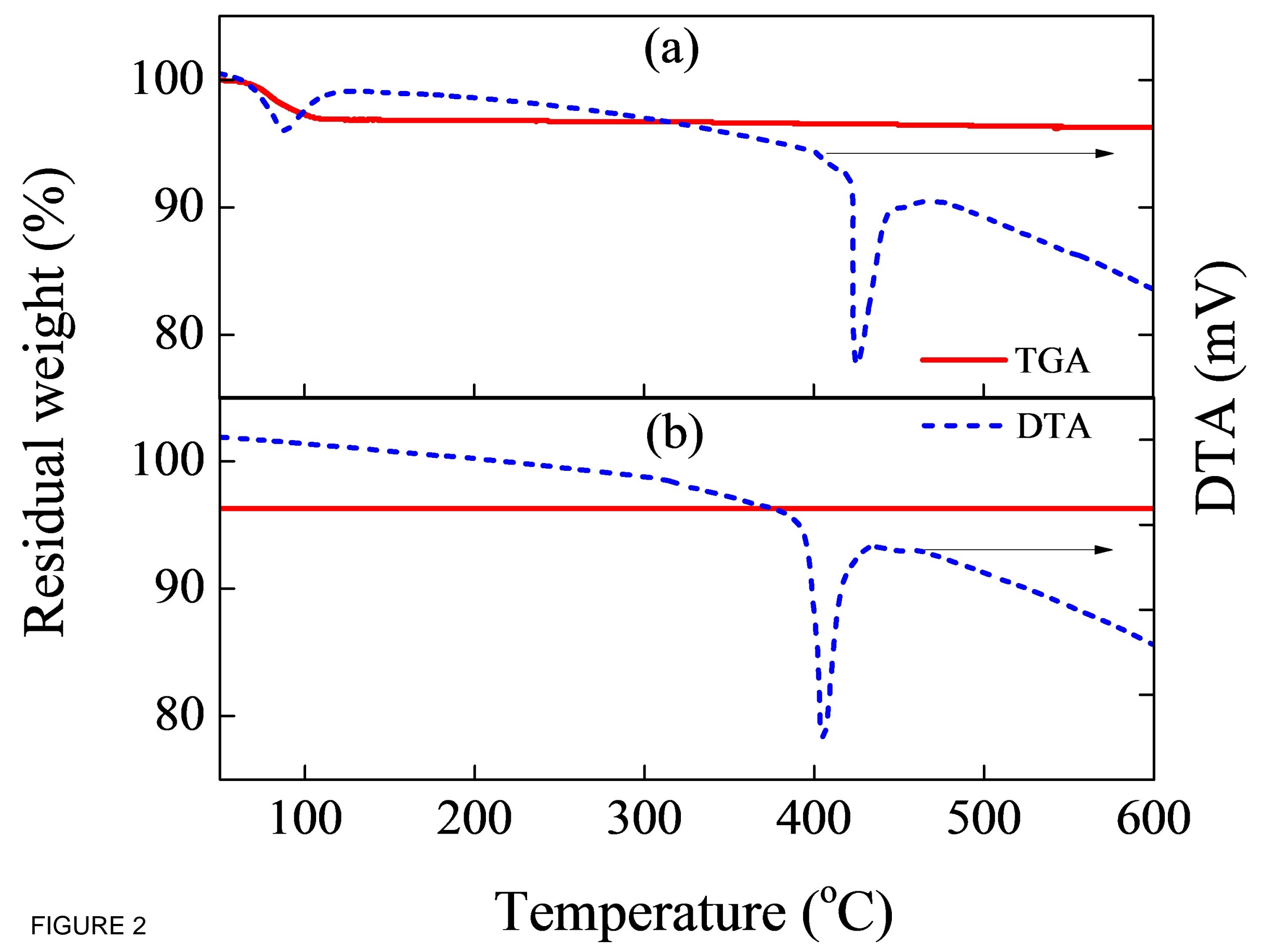




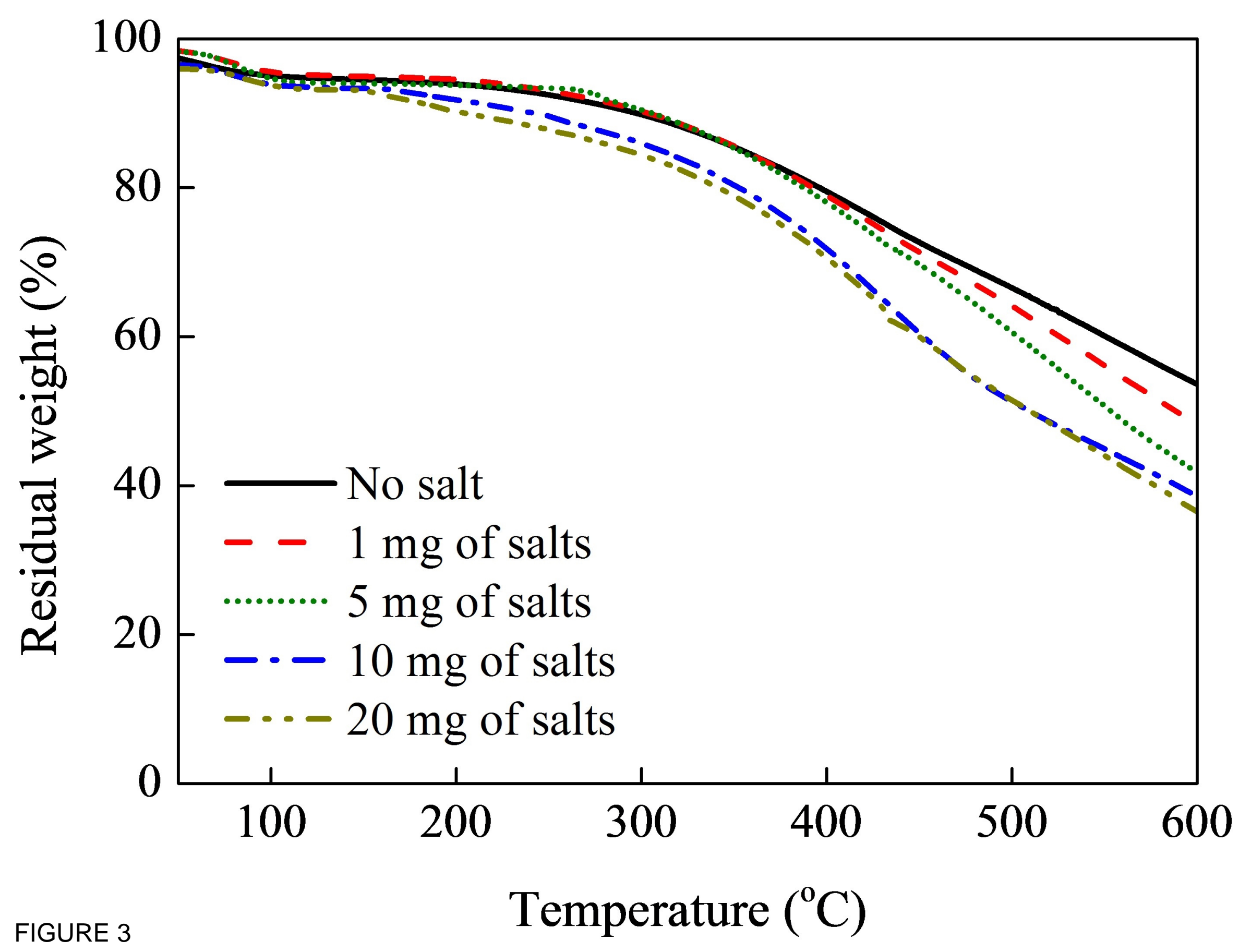


(a)

(b)

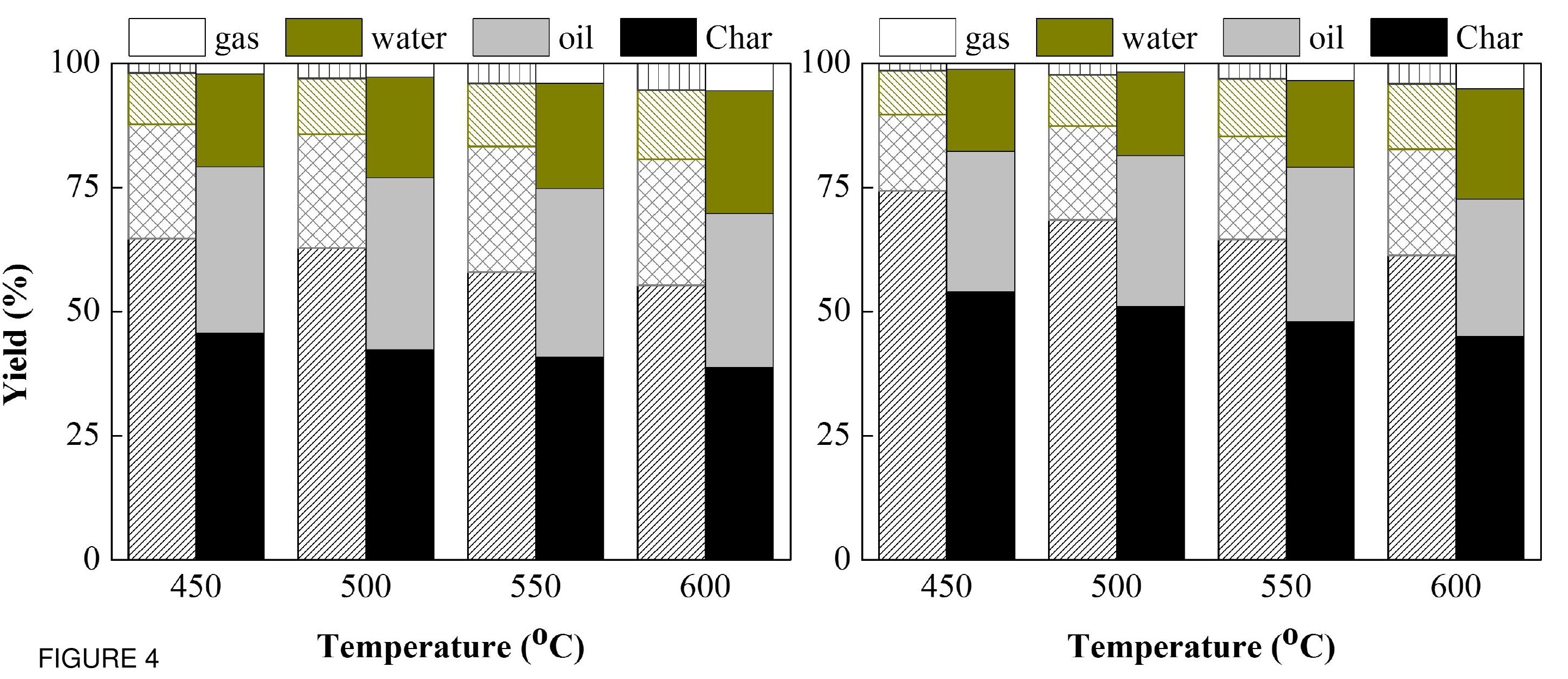




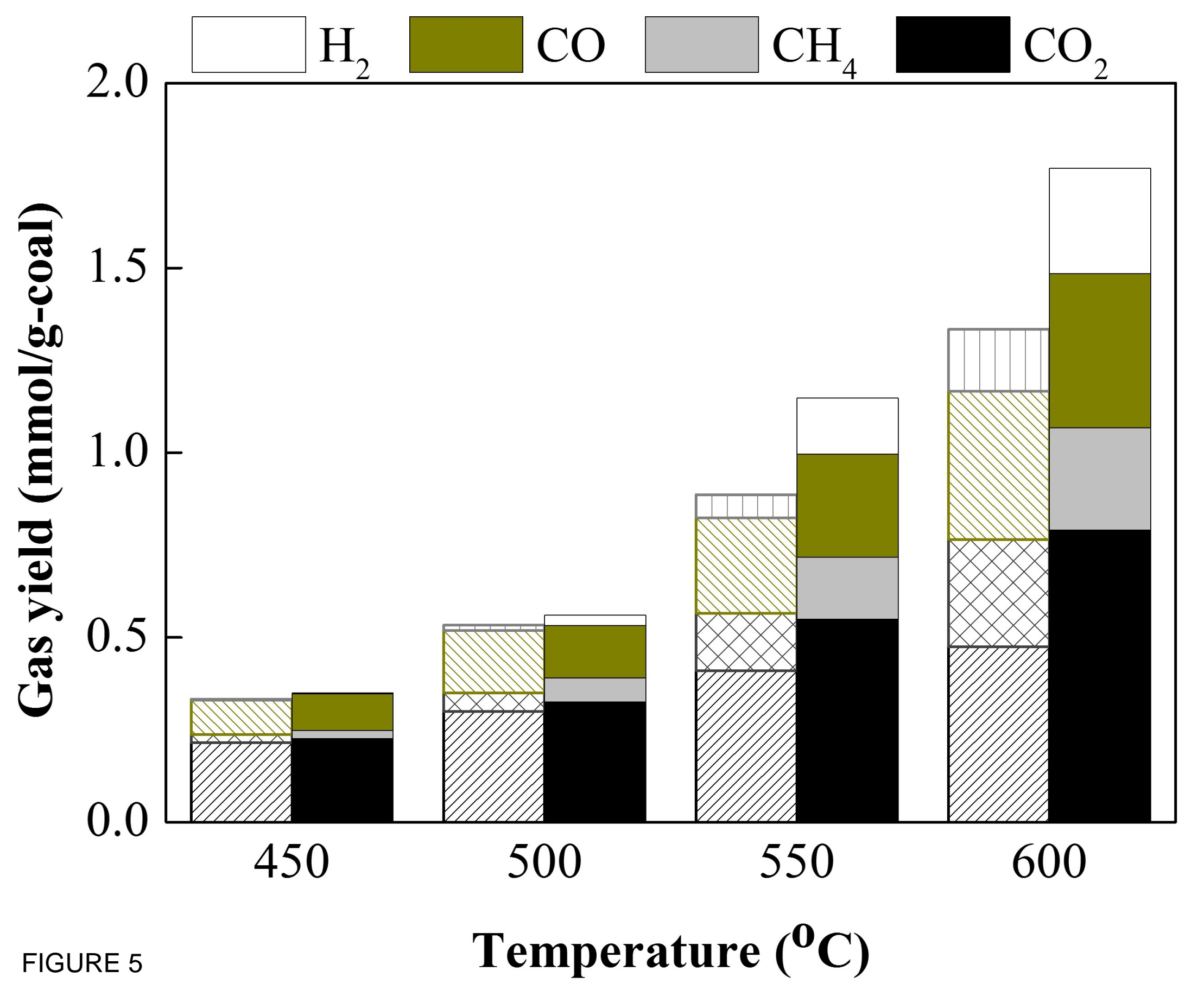


Table 1

\begin{tabular}{lcc}
\hline & $\begin{array}{c}\text { Xinghe } \\
\text { coal }\end{array}$ & $\begin{array}{c}\text { Loy yang } \\
\text { coal }\end{array}$ \\
\hline Proximate analysis (\%-d*): & & \\
Ash & 11.9 & 1.6 \\
Volatile matter*** & 41.0 & 51.5 \\
Fixed carbon & 47.1 & 46.9 \\
\hline Ultimate analysis (mass\%-d.a.f**) & & \\
C & 69.1 & 67.3 \\
H & 4.6 & 4.9 \\
O*** & 20.6 & 26.9 \\
N & 1.0 & 0.9 \\
S & 4.7 & - \\
\hline
\end{tabular}

*dry base; **dry ash-free base; ***by difference 
Table 2

\begin{tabular}{|c|c|c|c|c|c|}
\hline \multirow{2}{*}{$\begin{array}{l}\text { Ret. time } \\
\text { (min) }\end{array}$} & \multirow{2}{*}{ Chemical name } & \multicolumn{4}{|c|}{$\%$-area } \\
\hline & & $450^{\circ} \mathrm{C}$ & $500{ }^{\circ} \mathrm{C}$ & $550^{\circ} \mathrm{C}$ & $600^{\circ} \mathrm{C}$ \\
\hline 1.569 & 2-Butanone & 2.46 & & 2.9 & 3.14 \\
\hline 1.834 & Benzene & 10.59 & 12.41 & 13.08 & 14.19 \\
\hline 1.96 & Cyclopentane, 1,2-dimethyl-, cis- & 1.87 & 2.2 & 1.82 & 1.97 \\
\hline 2.541 & Toluene & 8.46 & 9.93 & 7.2 & 7.81 \\
\hline 2.73 & 1-Octene & 1.79 & 2.1 & 1.62 & 1.76 \\
\hline 2.815 & Hexane, 2,4-dimethyl- & 1.35 & 1.52 & 2.01 & 2.11 \\
\hline 3.265 & 2-Pentanone, 4-hydroxy-4-methyl- & 7.59 & 8.91 & 7.12 & 7.67 \\
\hline 3.65 & o-Xylene & 5.58 & 6.55 & 5.58 & 6.05 \\
\hline 3.895 & 1-Nonanol & 1.96 & 2.3 & 1.7 & 1.85 \\
\hline 3.964 & o-Xylene & 3.02 & 3.55 & 3.05 & 3.31 \\
\hline 4.01 & 4,4-Dimethyl octane & 1.25 & 1.47 & 1.81 & 1.97 \\
\hline 5.135 & Phenol & 7.37 & 8.65 & 4.97 & 5.39 \\
\hline 5.338 & Cyclopropane, nonyl- & 1.81 & 2.12 & 1.2 & 1.29 \\
\hline 5.422 & Benzene, 1,2,3-trimethyl- & 2.82 & 3.31 & 2.85 & 3.07 \\
\hline 5.47 & Undecane & 2.06 & 2.42 & 2.31 & 2.48 \\
\hline 5.878 & Benzene, 1,2,3-trimethyl- & 1.48 & 1.73 & 2.11 & 1.98 \\
\hline 6.231 & Phenol, 2-methyl- & 0.82 & & 3.47 & 3.76 \\
\hline 6.288 & Phenol, 2-methyl- & 3.51 & 4.13 & & \\
\hline 6.6 & p-Cresol & 9.28 & 10.9 & 7.04 & 7.63 \\
\hline 6.898 & 1-Tridecene & 2.05 & 2.31 & 2.3 & \\
\hline 7.028 & Pentadecane & 0.96 & & 1.47 & 1.59 \\
\hline 7.771 & Phenol, 3,5-dimethyl- & 2.85 & 3.29 & & 2.53 \\
\hline 8.455 & $\begin{array}{l}\text { Cyclobutane, } \\
\text { 3-hexyl-1,1,2-trimethyl- }\end{array}$ & 2.73 & 2.8 & 3.28 & 3.5 \\
\hline 8.581 & Tetradecane & 1.45 & & 1.37 & 1.49 \\
\hline 11.503 & Heneicosane & 1.02 & & & 2.25 \\
\hline 12.854 & Heptadecane & 1.53 & 1.78 & 1.18 & \\
\hline 14.13 & Heneicosane & 1.07 & & 2.07 & \\
\hline 14.18 & Naphthalene, 1,4,6-trimethyl- & 1.46 & 1.36 & 1.64 & \\
\hline
\end{tabular}




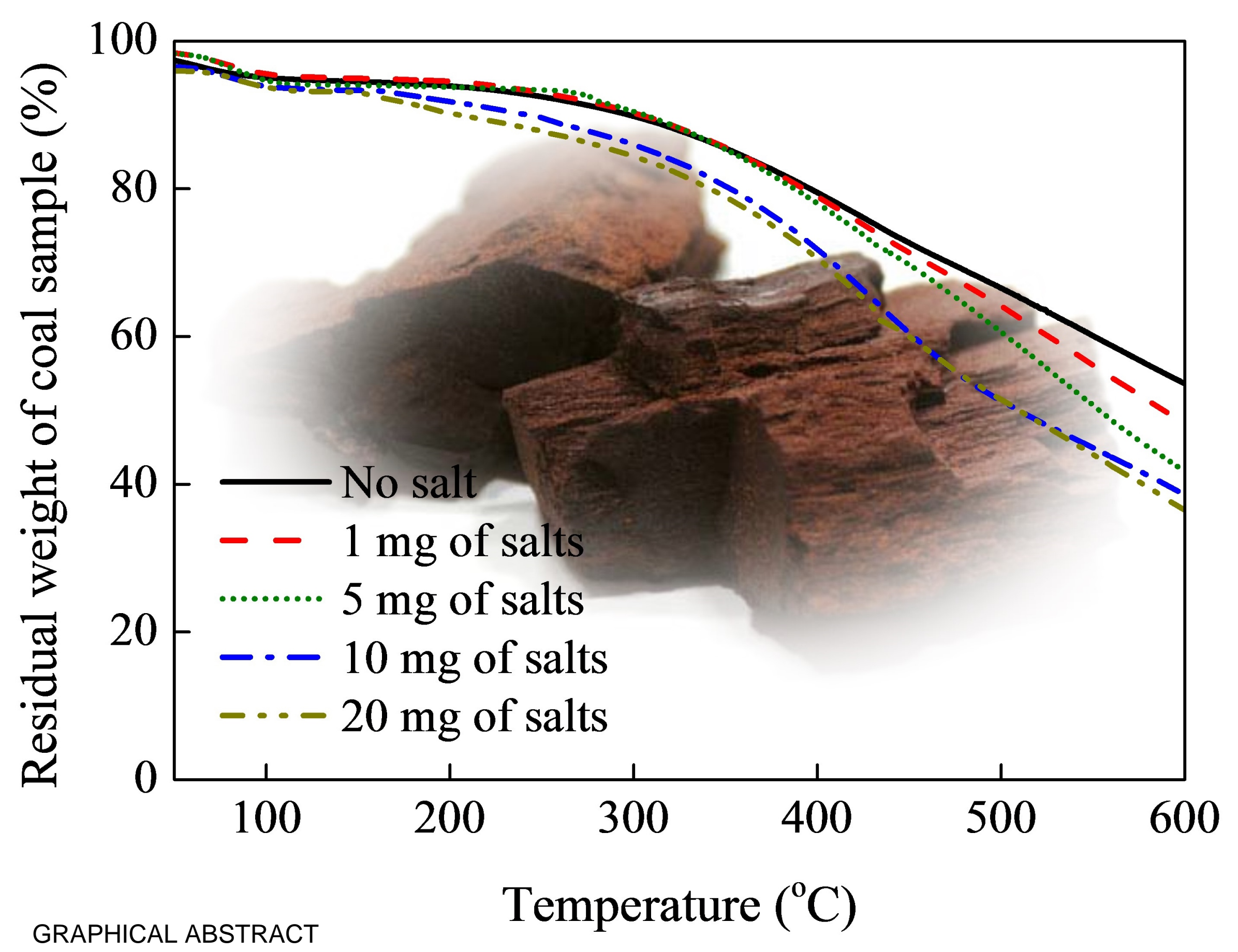

